\title{
The Impact of Calculating Environmental Cost on Purchase and Sale of Electricity
}

\author{
Xiao Zhanhui ${ }^{1}$, Liu Dunnan ${ }^{2}$, Zhou Long ${ }^{1}$, Wang Qiang ${ }^{2}$ \\ ${ }^{1}$ Guangdong Power Grid Corporation, Guangzhou City 510600, P.R. China \\ ${ }^{2}$ North China Electric Power University, Beijing 102206, P.R. China
}

\begin{abstract}
The control of environmental cost can gain the maximum of economic benefits and environmental benefits in the process of electricity trading. In this paper, the benefit of environmental protection is summarized and the measuring method of environmental cost is given so that the cost of resource consumption and pollution control can be study by using it. The analysis of how the environmental cost impacts electricity trading is made in the paper. In the end, the paper presents a method of caculating electricity trading based on the externality of trading.
\end{abstract}

\section{Introduction}

The change of global climate has become the main threat to the human society in ref [1]. Electricity, a secondary energy source producted by burning fossil fuels, is the main source of pollution. It is of great significance to reduce the pollution of the environment cost and solve the energy crisis.

In electric power enterprises to carry out the energy conservation and emissions reduction, and optimize the structure of power, increase the clean energy power generation, increase the power ratio of thermal power electricity access to control greenhouse gas emissions in China, is of great significance to reduce the pollution of the environment cost, is also China to solve energy crisis and the processing of the important methods for environmental pressures [2-4].

There is a brief on the significance of energy-saving power generation dispatching in ref [5]. Ref [6-7] is involved in the influence of grid structure, energy conservation and environmental protection on power grid and give some suggestions about the problem in carrying out energy-saving dispatching. There is a benefit compensation mechanism based on electricity power distribution auction model in ref [8].

The research about electric power market transaction in this paper is based on the existing research results. Firstly, the measurement methods of environmental cost is summarized. Then make a research on resource consumption cost and pollution control cost and calculate the comprehensive environment cost. Finally, the impact of environment cost on electricity trading is analyzed in the paper.

\section{The definition of the benefit of environmental protection}

The benefit of environmental protection is the reduction environmental cost due to the decrease of pollutant caused by adjusting of trading strategy. It can be divided into two types which are pure environmental benefit and relative environmental benefit respectively.

(1) If reducing pollutant emission in local make the whole regional emission down after the electricity trading.
Then this benefit calls pure environmental benefit which broght by two transactions sides and influences the whole regional.

(2) If the trading only benefits the power grid and makes the local emission down, then the benefit calls relative environmental benefit which means trading dosen't affect the whole regional but it can produce benefit for the grid.

Therefore, it is necessary to define the cost of environmental protection. Environmental benefit means the balance of environmental protection cost because of trading. The cost of low carbon means environmental protection cost in the paper.

\section{Environmental cost calculation method}

This section describes the structure and measurement of environmental cost.

Electricity production process will have adverse effect on environment. The cost environmental governance will also increase as time goes on. Therefore, the total cost of the electric power production should be the sum of production cost and environment cost (as shown in figure 1).

$$
C_{T}=C_{P}+C_{E}
$$

In the formula, $C_{T}$ means total cost; $C_{P}$ means production cost which equals fixed cost plus variable cost; $C_{E}$ means environment cost. 


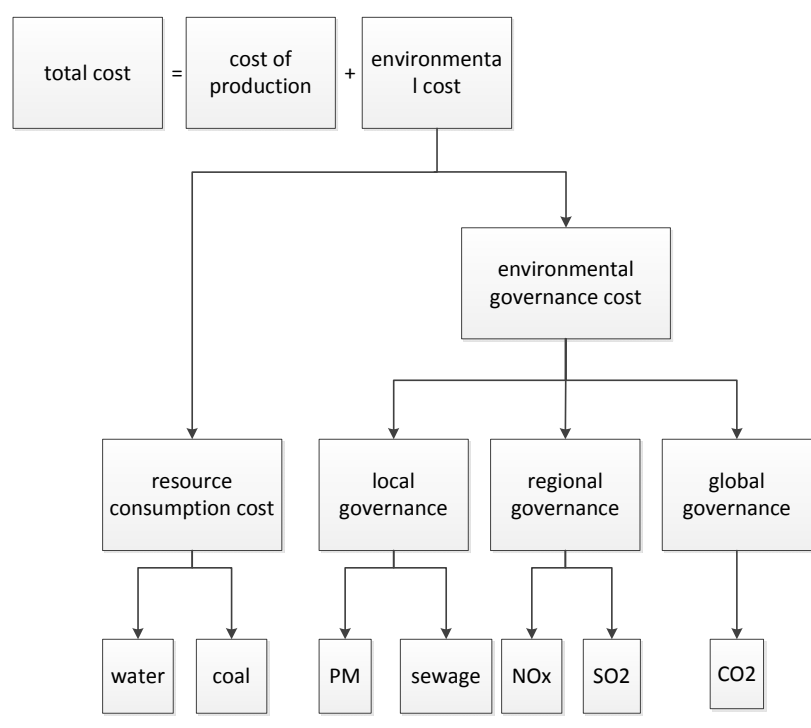

Fig1. The total cost of electric power production

The environment cost of electricity production contains resource consumption cost and pollution control cost. Resource consumption cost is caused by the longterm adverse effects on environment due to the consumption of energy resources such as water and coal. It will be reflected as resource tax. Pollution control cost is produced by controlling the discharge of pollutants in the process of electric power production. It contains local governance cost, regional governance cost and global governance cost. Local governance cost refers to the adjacent discharge point such as sewage, particles; Regional governance cost refers to the pollution that far away from the discharge point, mainly for the gas emission, including SO2, CO2 and NOx. The cost of global governance refers to the cost of greenhouse gas emission, mainly for CO2.

The environmental cost of electricity production $C_{E}$ is:

$$
\begin{aligned}
& C_{E}=C_{r}+C_{p} \\
& =\left(c_{\text {water }} \times C_{\text {coal }}\right)+C_{\mathrm{CO}_{2}}+C_{\mathrm{SO}_{2}}+C_{\mathrm{NO}_{2}}+C_{P M}+C_{\text {sewage }}
\end{aligned}
$$

In the formula, $C_{\text {water }}$ and $C_{\text {coal }}$ mean water resource consumption cost and coal resource consumption cost; $c_{\mathrm{SO}_{2}}$ means the cost for eliminating the influence of sulfur dioxide emission in the process of electric power production.

The model of environment cost is got by calculating various factors of environment cost. Figure 2 is based on comprehensive environment cost analysis and calculation steps of power grid.

(1) Research and measure the data of generated energy, resource consumption and quantity of pollutant discharged and then get various factors of environment including water consumption rate factor, coal consumption rate factor, sewage, carbon dioxide, sulfur dioxide, nitrogen oxides and solid particulates factors.
(2) Compare and measure each country's resource tax, carbon tax and pollution discharge fees and then confirm the various equivalent environment cost including water and coal resource tax and equivalent emission cost of various pollutants.

(3) All kinds of environment cost of unit electricity, obtained by multiplying environment factors and environmental cost equivalent, includes water resources, coal resources cost and the cost of governance emission. (Unit: yuan/kWh);

(4) The aggregation of all kinds of environment cost per electricity can get electricity comprehensive environment cost (Unit: yuan/kWh);

(5) The environment cost of trading power can be got by multiplying comprehensive environment cost and purchasing power.

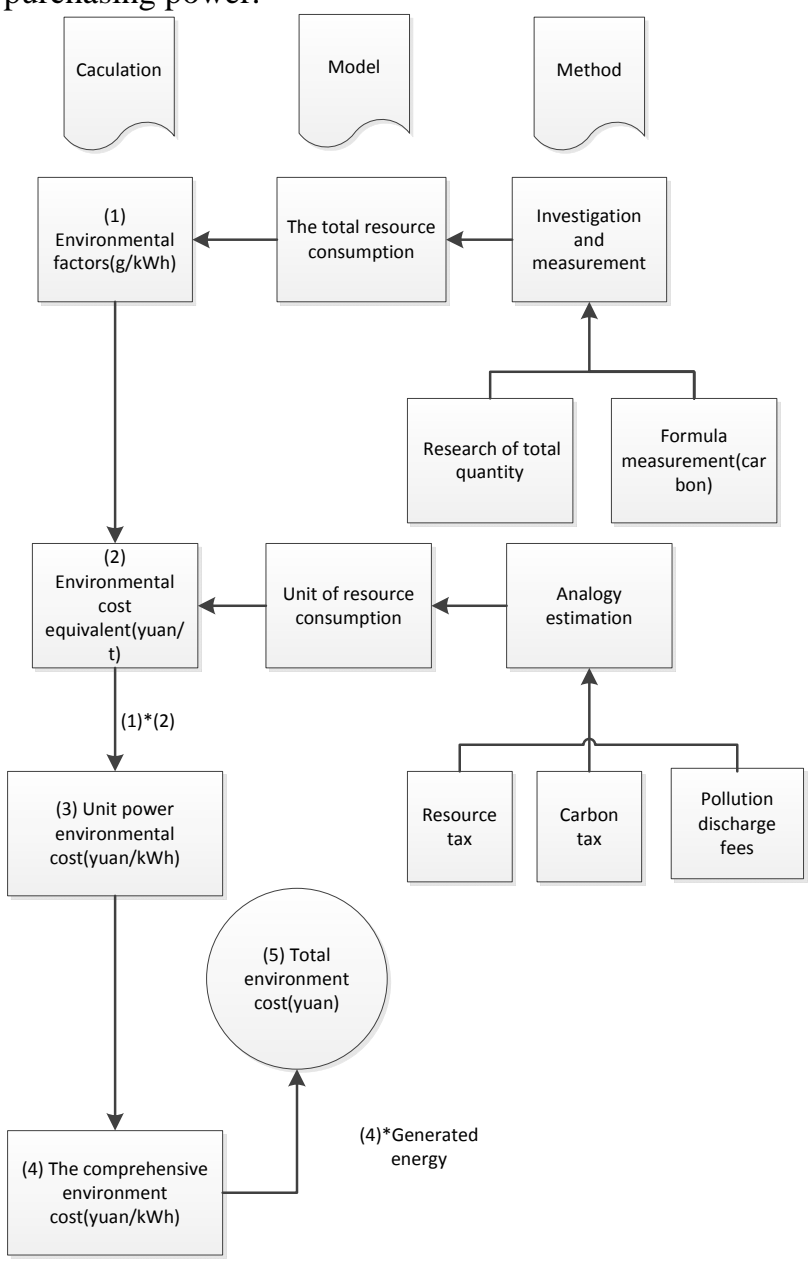

Fig2. The process of environmental cost

\subsection{The measurement of resource consumption equivalent cost}

Resource consumption equivalent cost, reflected as resource tax, is used to measure the adverse effects caused by primary energy consumption except the cost of production. As shown in table 1, different types of primary energy resources have different resource tax. 
Table1. The range of China resource tax tax

\begin{tabular}{|ll|l|}
\hline \multicolumn{2}{|c|}{ Tax items } & Tax range \\
\hline 1. & Crude oil & 8-30yuan/t \\
\hline 2. & Natural gas & $2-15 y$ yan/ kilostere \\
\hline 3. & Coal & $0.3-5 y u a n / t$ \\
\hline 4. & Other ores & $0.5-20 y u a n / t$ \\
\hline 5. & Black metal ores & $2-30 y u a n / t$ \\
\hline 6. & $\begin{array}{l}\text { Non-ferrous } \\
\text { metal ores }\end{array}$ & $0.4-30 y u a n / t$ \\
\hline 7. & Salt & -- \\
\hline 8. & Solid salt & $10-60$ yuan/t \\
\hline 9. & Liquid salt & $2-10$ yuan/t \\
\hline
\end{tabular}

\subsection{The measurement of pollution control equivalent cost}

Measure the pollutant emission (e.g., sewage, carbon dioxide, sulphur dioxide, nitrogen oxides, and solid particles) management cost with the equivalent cost of pollution control class。 It can be reflect by carbon tax and emissions trading prices or discharge.In the problem which the discharge fees of management wastewater, only a sewage disposal if the discharging standard. While collect sewage discharge if it contains one class pollutants. Sewage discharge equals to the sum of the first 3 items pollution equivalent number of pollutants 0.7 times.The first and second pollution classified according to the integrated wastewater discharge standard (GB8978-1996). We need to add 1 times on the basis of the original discharge for excessive pollutionThe current carbon control tax is set as 10 to 50 yuan per tonne of carbon dioxide because high carbon tax may strikes national economy and enterprise adaptability. The fees of controlling sulfur dioxide, nitrogen oxides and solid particles is based on 《 Discharge levy standard management approach》 .

\section{The measurement of comprehensive environment cost}

\subsection{The analogy estimation of equivalent cost}

According to the resource tax, carbon tax and emission trading mechanisms which foreign have implemented, it can be analogy estimated to determine resource tax and various equivalent cost of pollutants emission based on China's actual economic development. Take coal for example, the comparison of the typical developed countries and China's tax is as shown in table 2.
Table2. The range of China resource tax

\begin{tabular}{|c|c|c|c|}
\hline $\begin{array}{c}\text { Country/T } \\
\text { ax }\end{array}$ & $\begin{array}{l}\text { Resource } \\
\text { tax(coal) }\end{array}$ & Coal tax & Emission trading price \\
\hline America & $15 \%-30 \%$ & $\begin{array}{c}50- \\
80 y u a n / t\end{array}$ & \multirow{3}{*}{$\begin{array}{l}\text { emission permit } \\
\text { trading }\end{array}$} \\
\hline Japan & $50 \%$ & $\begin{array}{c}150- \\
\text { 250yuan/ } \\
\text { t }\end{array}$ & \\
\hline $\begin{array}{c}\text { European } \\
\text { Union }\end{array}$ & $15-70 \%$ & $\begin{array}{c}200- \\
\text { 300yuan/ } \\
\text { t }\end{array}$ & \\
\hline China & $0.3-5 y u a n / t$ & 0 & $\begin{array}{c}\text { some areas' emission } \\
\text { permit trading }\end{array}$ \\
\hline
\end{tabular}

\subsection{The calculation of environment cost}

The resources cost of unit water consumption and coal consumption and the management costs of unit emission of sewage, carbon, sulfur, nitrate, and smoke are obtained by calculating the equivalent cost. The calculation of environment cost is shown as follows.

$$
\begin{aligned}
& C_{\text {com }}=C_{r}+C_{p}=f_{r} \times e_{r}+f_{p} \times e_{p} \\
& =f_{\text {water }} \times e_{\text {water }}+f_{c} \times e_{c}+f_{\text {sewage }} \times e_{\text {sewage }} \\
& +f_{\mathrm{CO}_{2}} \times e_{\mathrm{SO}_{2}}+f_{\mathrm{NO}_{2}} \times e_{\mathrm{NO}_{2}}+f_{P M} \times e_{\mathrm{PM}}
\end{aligned}
$$

In the formula, $\mathrm{Cr}, \mathrm{Cp}$ mean unit of electricity resource consumption and pollution control cost.

The total environment cost is shown as follows.

$$
\begin{aligned}
& C_{\text {com }}=C_{r}+C_{p}=f_{r} \times e_{r}+f_{p} \times e_{p} \\
& =f_{\text {water }} \times e_{\text {water }}+f_{c} \times e_{c}+f_{\text {sewage }} \times e_{\text {sewage }} \\
& +f_{\mathrm{CO}_{2}} \times e_{\mathrm{SO}_{2}}+f_{\mathrm{NO}_{2}} \times e_{\mathrm{NO}_{2}}+f_{\mathrm{PM}} \times e_{\mathrm{PM}}
\end{aligned}
$$

In the formula, $C_{\text {com }}$ is the total environment cost and $Q_{E}$ is the transacted electricity.

\section{The impact of environment cost on electricity trading}

(1)The compensation of trading environment cost -", , , 0"

"+": If local thermal power solds electricity to other places, then the local bears the consumption of resource and the discharge of pollutant and their transaction price should contain environment cost such as $0.4 \mathrm{yuan} / \mathrm{KWh}$ (electricity price)+0.2yuan/KWh environment cost;

"-": If local purchases the electricity from other places, then other places bear the consumption of resource and the discharge of pollutant and their transaction price should take out environment cost such as $0.4 y u a n / K W h$ (electricity price)-0.2yuan $/ \mathrm{KWh}$ environment cost; 
" 0 ": If local sales the clean energy to other places, then there are no environment cost such as 0.4yuan/KWh (electricity price) +0 yuan/KWh environment cost because it does not discharge any pollutant.

The overall compensation principle: The local cost is calculated as the actual consumption and the regional cost is calculated as the apportionment method.

(2)The model of apportionment and compensation

The environment cost compensate according to trade contract at the bilateral trade. The environmental cost apportion according to the electricity consumption at the centralized trading.

\section{Conclusion}

Electric power industry has promoted the development of China's economic and social, but at the same time it also has serious negative effect on people life. Therefore, the subconscious mind of environmental protection at each link of power system is extremely necessary when carrying out the strategy of the sustainable development of the power system. In this paper, the impact of calculating environmental cost on purchase and sale of electricity is analyzed based on the comprehensive external cost of controlling environmental pollution at the process of electricity trading. A new perspective based on environmental constraint is given in the paper to optimize the allocation of resources at the electricity trading.

\section{References}

[1] KANG Chongqing, CHEN Qixin, XIA Qing. Prospects of low-carbon electricity. Power System Technology, 2009, 33(2):1-7.

[2] DING Junwei, XIA Qing, HU Yang, et al. New model for gradually establishing competitive generation market.Proceedings of the CSEE, 2003, 23(3): 10-15.

[3] LI Canbing, KANG Chongqing, XIA Qing, et al. Study on trading mechanism of regional electricity market. Power System Technology, 2004, 28(7): 3439.

[4] SHANG Jincheng, HUANG Yonghao, KANG Chongqing, et al. Coordination models and methods of multistage electricity market. Automation of Electric Power Systems, 2004, 28(6):19-24.

[5] QI Dacai, XIA Qing, LU Qiang, et al. Criteria of monopoly power on market price in generation markets. Automation of Electric Power Systems, 2003, 27(5): 26-30.

[6] SONG Yonghua, YANG Xia, SUN Jing. Smart grid of low-carbon, high efficiency, security and reliability. Energy of China, 2009, 31(10): 23-27.

[7] SHI Jianhua, TAN Sumei. Algorithm of energy saving generation dispatch scheduling. Automation of Electric Power Systems, 2008, 32(24): 48-51.

[8] GRUBB M, JAMASB T, POLLITT M G. Delivering a low-carbon electricity system. Cambridge, UK: Cambridge University Press, 2008. 